\title{
ORIGINAL ARTICLE \\ Epidemiology of traumatic cervical spinal cord injury in Tianjin, China
}

\author{
Q Wu ${ }^{1}$, Y-L Li ${ }^{1}$, G-Z Ning, S-Q Feng, T-C Chu, Y Li, Y Hao and Q-L Wu
}

\begin{abstract}
Study design: A retrospective epidemiological study.
Objective: To describe the recent epidemiological characteristics of traumatic cervical spinal cord injury (TCSCI) in adults in Tianjin. Setting: Tianjin Medical University General Hospital.

Methods: This study included all TCSCI patients aged $\geqslant 15$ years who were admitted to a general hospital from December 2008 to November 2011. Epidemiological characteristics including gender, age, marital status, occupation, etiology, level of injury, severity and America Spinal Injury Association (ASIA) impairment scale were recorded.

Results: A total of 143 patients with TCSCl were included in the study. Mean age was $54.6 \pm 14.6$ years (men $53.5 \pm 14.9$ years, women $54.2 \pm 12.1$ years), with a range of 18-87 years, and the male/female ratio was $5: 1$. The leading cause was falls (49.7\%), followed by motor vehicle accidents (36.4\%). The most common injury site was C5, accounting for $42 \%$. In all, 74 (51.7\%) patients had complications; the most common complication was hyponatremia (30.1\%), followed by urinary infection (23.1\%), respiratory infection (18.2\%), bedsore (9.8\%) and deep venous thrombosis (4.9\%). As for the severity, ASIA grade D was encountered most frequently. Six patients died, five of whom died from respiratory failure.

Conclusion: The epidemiology of TCSCI has its own characteristics. Falls were the leading causes, and TCSCI occurred most frequently in the middle-aged and elders. Therefore, establishing public policies aimed at preventing injuries should focus on falls and more attention should be paid to the aged regarding their vulnerability to low fall. Additionally, complications should be prevented in TCSCI patients.
\end{abstract}

Spinal Cord (2012) 50, 740-744; doi:10.1038/sc.2012.42; published online 24 April 2012

Keywords: trauma; cervical spinal cord injury; epidemiology; China; prevention

\section{INTRODUCTION}

Traumatic spinal cord injury (TSCI) is a life-threatening condition that not only leads to loss of motor and sensory below the level of injury but also results in many dysfunctions of many organs, including the respiratory, gastrointestinal, urinary and autonomic nervous system. It is a substantial burden to the affected individuals, their families and society, because of expenses towards health-care treatments, rehabilitation and lost productivity. ${ }^{1,2}$ Of the TSCIs, traumatic cervical spinal cord injury (TCSCI) is one of the most severe and disabling traumatic conditions. Worldwide, the global estimate of TSCI incidence lies between 10.4 and 83 per million per year; ${ }^{3}$ however, TCSCI is the most common injury (accounting for $>50 \%)_{.}^{4,5}$ Every year, 11000 cervical spinal cord injury patients require hospitalization. ${ }^{6}$ The mean length of stay of patients with TCSCI (161 days for Frankel grade A, B or C and 102 days for grade D) is longer than that for thoracic (161 days for Frankel grade A, B or C and 64 days for grade D) and lumbar (138 days for Frankel grade A, $\mathrm{B}$ or C and 70 days for grade D) TSCI. ${ }^{7}$ The TCSCI patients have the highest costs, and the complications are significantly of longer duration. ${ }^{8,9}$ Approximately $20.6 \%$ of the TCSCI cases require tracheostomy because of compromised respiratory function. ${ }^{10}$ Additionally, TCSCI mortality (72\%) is also obviously higher than that for thoracic $(20.7 \%)$ and lumbar (7.3\%) TSCI. ${ }^{11}$
China is the largest developing country, accounting for an estimated $25 \%$ of the world's population. Tianjin is the third largest city in China, with a total population of about 12938200 (2011). In our previous investigation, ${ }^{12,13}$ consistent with the global trend, TCSCI was the most common neurological level of injury. Although TCSCI is the most prevalent and severe condition, few reports have been published on TCSCI. To our knowledge, no local epidemiological research on TCSCI has been extensively carried out.

The purpose of this study was to describe the epidemiological features of TCSCI in China with reference to etiological factors, gender, the most common age group involved, level of injury, marriage and America Spinal Injury Association (ASIA) score, and to make planning strategies to reduce TCSCI incidence.

\section{MATERIALS AND METHODS}

This retrospective study was conducted in TCSCI patients admitted to Tianjin Medical University General Hospital, the biggest general medical center in Tianjin, between December 2008 and November 2011. Detailed information was obtained from the medical records of all patients discharged from this hospital with a diagnostic code ICD10, including age, sex, date of admission, causes of injury, level of injury, ASIA score, date of discharge and so on. Exclusion criteria were age 0-14 years and incomplete medical records, or medical records with uncertain diagnosis. A total of 143 cases were included in this study.

Department of Orthopaedics, Tianjin Medical University General Hospital, Tianjin, People's Republic of China

${ }^{1}$ These authors contributed equally to this work and should be considered co-first authors

Correspondence: Professor S-Q Feng, Department of Orthopaedics, Tianjin Medical University General Hospital, Tianjin Heping District Anshan Road 154, Tianjin 300052, People's Republic of China

E-mail: fengsq321@gmail.com

Received 9 January 2012; revised 20 February 2012; accepted 4 March 2012; published online 24 April 2012 
In this survey, like in our previous studies, ${ }^{12,13}$ the patients were divided into seven age groups: $15-24,25-34,35-44,45-54,55-64,65-74$ and $\geqslant 75$ years. Marital status was categorized as married and unmarried; the causes of TCSCI were divided into motor vehicle collision, falls, including low falls (on the same level, or from a height of $<1 \mathrm{~m}$ ) and high falls (from a height of $>1 \mathrm{~m}$ ), struck by an object, sport-related injuries, assault, work accident and other causes. The neurological deficits were classified according to the ASIA classification. These data were collected in a Microsoft Excel spreadsheet.

\section{RESULTS}

Age

Gender and age distributions are shown in Table 1. For the 143 cases, the largest age group was 55-64 years, accounting for 29.4\%, followed by $45-54$ years $(28.7 \%)$. Mean age was $54.6 \pm 14.6$ years (men $53.5 \pm 14.9$ years, women $54.2 \pm 12.1$ years), with a range of $18-87$ years.

\section{Gender}

Over the study periods, though the frequency of TCSCI increased in both men and women, the male/female ratio of the four periods decreased slightly. On an average, 119 of the patients were male and 24 were female. The male/female ratio was 5:1.

\section{Marital status}

As shown in Table 1, >90\% of all TCSCI patients were married.

\section{Occupations}

The occupations of patients, at the time of TCSCI, included retired $(27.3 \%)$, peasants $(32.2 \%)$, workers $(26.6 \%)$, drivers $(4.9 \%)$, teachers $(4.2 \%)$ and students (4.2\%).

\section{Cause of injury}

From the results, falls exceeded road accidents as the leading cause of injury, accounting for $49.7 \%$ of all TCSCI. Motor vehicle accidents (MVA) were the second most common cause of TCSCI, accounting for $36.4 \%$ on average. Other causes were being struck by an object $(4.9 \%)$, sport-related injury $(4.2 \%)$, work accident $(3.2 \%)$, assault (1.4\%) and others (1.4\%).

In the low-falls group, the incidence rate of TCSCI steadily increased with age (20\% for the age group 16-35 years to $66.7 \%$ for the age group $>75$ years). In the high-falls group, the incidence rate tended to decrease with age (Figure 1).

\section{Level of injury}

The neurological level of TSCI in this study is presented in Figure 2. Over the study years, the most common vulnerable level was the C5 segment, accounting for $50 \%$ of the TCSCI cases, followed by the C6 segment.

\section{ASIA grade}

During the study periods, all patients suffered from neurological deficits of varying degree (Table 1). A total of 84 patients $(59 \%)$ presented with ASIA grade D, followed by grade C (19\%), grade B (17\%) and grade A (5\%).

\section{In-hospital mortality and the cause of death}

A total of six patients ( $4.2 \%$ of admissions) died during hospitalization, all of whom were male. Among the patients, 3 (50\%) were aged $>60$ years at the time of injury, 3 patients $(50 \%)$ were retired and 3 of the patients $(50 \%)$ were injured after a motor vehicle accident.
In the end, five died from respiratory failure and one died from acute pulmonary embolism.

\section{Associated trauma and degeneration of cervical vertebra}

In all, $43.4 \%$ of the patients had associated trauma, the commonest was head injury $(30.8 \%)$, followed by extremity fractures and hydrothorax. More than $56 \%$ of the TCSCI patients had no associated trauma; however, $76.9 \%$ of the patients had degenerative changes of cervical vertebra (Table 1 ).

\section{Complications}

Of the 143 patients, $72(50.3 \%)$ patients had complications. As shown in Table 1, the most common complication was hyponatremia, accounting for $30.1 \%$ of the TCSCI, followed by urinary infection $(23.1 \%)$, respiratory infection $(18.2 \%)$, bedsore $(9.8 \%)$ and deep venous thrombosis (4.9\%). Moreover, as displayed in Table 2, the incidence of complications increased steadily with the severity (except the ASIA grade A).

\section{Spinal cord injury without radiographic abnormality}

During the study years, there were 24 cases of spinal cord injury without radiographic abnormality among 143 cases of TCSCI, which accounted for $16.8 \%$.

\section{DISCUSSION}

Nowadays, most epidemiology researches from countries worldwide focus on TSCI, but related information on TCSCI is limited. In comparison with TSCI, TCSCI has its own characteristics: long length of stay, high hospital cost and high mortality rate. To our knowledge, a national or local epidemiological study of TCSCI has not been reported previously in China.

In this study, the male/female ratio was $5: 1$, similar to that reported in early epidemiological studies in China. ${ }^{12,13}$ This might be because in most countries men are more engaged in dangerous work, while most of the women are housewives or engaged in occupations with low risk of injury.

As for age, in our study, most injuries occurred in the 45-65-year age group, which was not in accordance with the recent reports. In many countries, the high-risk groups for TSCI were the 20-50-year age groups. ${ }^{11,12}$ In addition, the mean age was 54.6 years, which is similar to the report on TCSCI in America (mean age 52 years). ${ }^{14}$ This is due to the increased number of aged people in China and because people are more prone to injury as they age and agility declines.

Historically, motor vehicle accident was the leading cause of TSCI in developed countries; however, the percentage of falls has rapidly increased in current years. In this study, low fall was the major cause of TCSCI. The reason was the presence of degenerative changes in the cervical spine. A striking feature of older patients is their propensity to suffer TCSCI from seemingly minor trauma (for example, low falls $<1 \mathrm{~m}$ ), because most of the older patients have degenerative changes of the cervical vertebra, including spondylosis and ossification of the posterior longitudinal ligament. Yoo et al. ${ }^{15}$ suggested that if there is marked stenosis of the cervical spinal canal, even an indirect minor trauma to the neck can cause irreversible changes in the spinal cord. Chikuda et al. ${ }^{16}$ reported that most of the cervical spinal cord injury cases associated with ossification of the posterior longitudinal ligament were incomplete, without bone injury and caused primarily by low-energy trauma. In China, there has been a high incidence of cervical degeneration that has resulted from the growth 
Table 1 Characteristics of TCSCI in adults living in Tianjin, China from December 2008 to November 2011

\begin{tabular}{|c|c|c|c|c|c|}
\hline & 2008 & 2009 & 2010 & 2011 & Total \\
\hline Number of cases & 33 & 37 & 36 & 37 & 143 \\
\hline Age (mean, s.d.) & $51.4,14.0$ & $53.8,15.9$ & $54.6,13.4$ & $54.3,15.5$ & $54.6,14.6$ \\
\hline $25-34$ & $1(3.0 \%)$ & $2(5.4 \%)$ & $3(8.3 \%)$ & $0(0)$ & $6(4.2 \%)$ \\
\hline $35-44$ & $2(6.1 \%)$ & $5(13.5 \%)$ & $3(8.3 \%)$ & $3(8.1 \%)$ & $13(9.1 \%)$ \\
\hline $45-54$ & $13(39.4 \%)$ & $8(21.6 \%)$ & $9(25.0 \%)$ & 11 (29.7\%) & $41(28.7 \%)$ \\
\hline$\geqslant 75$ & $1(3.0 \%)$ & $4(10.8 \%)$ & $2(5.6 \%)$ & 2 (5.4\%) & 9 (6.3\%) \\
\hline \multicolumn{6}{|l|}{ Gender } \\
\hline Male & $28(84.8 \%)$ & $31(83.8 \%)$ & $29(80.6 \%)$ & 31 (83.8\%) & 119 (83.2\%) \\
\hline Female & $5(15.2 \%)$ & $6(16.2 \%)$ & 7 (19.4\%) & $6(16.2 \%)$ & $24(16.8 \%)$ \\
\hline \multicolumn{6}{|l|}{ Marital status } \\
\hline Married & $30(90.9 \%)$ & $34(91.9 \%)$ & $35(97.2 \%)$ & 35 (94.6\%) & $134(93.7 \%)$ \\
\hline MVA & $12(36.4 \%)$ & $8(21.6 \%)$ & $14(38.9 \%)$ & $18(48.6 \%)$ & $52(36.4)$ \\
\hline Work accident & $2(6.1 \%)$ & $1(2.7 \%)$ & $0(0 \%)$ & $0(0 \%)$ & $3(2.1 \%)$ \\
\hline Sport-related & $1(3.0 \%)$ & $1(2.7 \%)$ & $4(11.1 \%)$ & $0(0 \%)$ & $6(4.2 \%)$ \\
\hline Struck by object & $3(9.1)$ & $1(2.7 \%)$ & $2(5.6 \%)$ & $1(2.7 \%)$ & $7(4.9 \%)$ \\
\hline Assault & $0(0 \%)$ & $1(2.7 \%)$ & $1(2.8 \%)$ & $0(0 \%)$ & $2(1.4 \%)$ \\
\hline Other & $0(0 \%)$ & $2(5.4)$ & $0(0 \%)$ & $0(0 \%)$ & $2(1.4 \%)$ \\
\hline \multicolumn{6}{|l|}{ ASIA score } \\
\hline A & $3(9.1 \%)$ & $3(8.1 \%)$ & $0(0 \%)$ & 2 (5.4\%) & $8(5.6 \%)$ \\
\hline B & $4(12.1 \%)$ & $9(24.3 \%)$ & $0(0 \%)$ & $11(29.7 \%)$ & $24(16.8 \%)$ \\
\hline C & $5(15.2 \%)$ & $8(21.6 \%)$ & $8(22.2 \%)$ & $6(16.2 \%)$ & 27 (18.9\%) \\
\hline D & $21(63.6 \%)$ & $17(45.9 \%)$ & $28(77.8 \%)$ & $18(48.6 \%)$ & $84(58.7 \%)$ \\
\hline \multicolumn{6}{|c|}{ Degeneration of cervical vertebra } \\
\hline \multicolumn{6}{|l|}{ Complication } \\
\hline Urinary infection & $5(15.2 \%)$ & $11(29.7 \%)$ & $9(25.0 \%)$ & $8(21.6 \%)$ & $33(23.1 \%)$ \\
\hline Respiratory infection & $5(15.2 \%)$ & $10(27.0 \%)$ & $6(16.7 \%)$ & $5(13.5 \%)$ & $26(18.2 \%)$ \\
\hline Hyponatremia & $13(39.4 \%)$ & $11(29.7 \%)$ & $8(22.2 \%)$ & $11(29.7)$ & $43(30.1 \%)$ \\
\hline Bedsore & $4(12.1 \%)$ & $6(16.2 \%)$ & $1(2.8 \%)$ & $3(8.1 \%)$ & $14(9.8 \%)$ \\
\hline DVT & $1(3.0 \%)$ & $1(2.7 \%)$ & $4(11 / 1 \%)$ & $1(2.7 \%)$ & $7(4.9 \%)$ \\
\hline SCIWORA & $6(18.2 \%)$ & $4(10.8 \%)$ & $7(19.4 \%)$ & $7(18.9 \%)$ & $24(16.8)$ \\
\hline
\end{tabular}

Abbreviations: ASIA, America Spinal Injury Association; DVT, deep venous thrombosis; MVA, motor vehicle accidents; SCIWORA, spinal cord injury without radiographic abnormality; $\mathrm{TCSCl}$, traumatic cervical spinal cord injury.

of aging in recent years, so the number of low falls-induced TCSCI would increase gradually.

With respect to the frequency of TCSCI according to profession, reports are rare. In this study, it was highest in peasants, followed by retired citizens, and then workers, which is different from the reports on TSCI. A study on TSCI from Turkey ${ }^{17}$ reported that the largest occupational group was employed $(71.8 \%)$, followed by housewives $(13.5 \%)$. In our previous study on TSCI, ${ }^{12}$ unemployed individuals were the largest group, followed by peasants and workers. These differences might attributed to the differences in economic conditions and the society.
Regarding the ASIA grade, our data showed that ASIA grade D was in majority during the study years, which is consistent with our previous report on TSCI. This is because patients with low falls as the cause are more likely to incur less damage in contrast to patients who are involved in more serious injuries, such as motor vehicle crashes or fall from $>1 \mathrm{~m}$ height.

The data revealed that the most common injury site was C5, followed by C6. These findings are in agreement with Bangladesh's studies, ${ }^{18}$ which indicate a high frequency of C5 and C6 injuries. This should be attributed to the relatively poor mechanical stability of cervical vertebra that makes the cervical spine more vulnerable to 


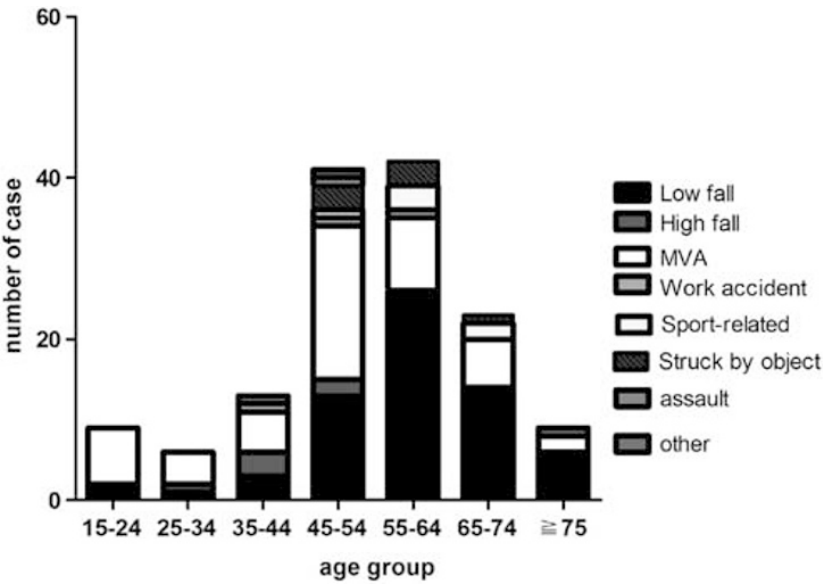

Figure 1 Causes of TCSCl classified by the age group.

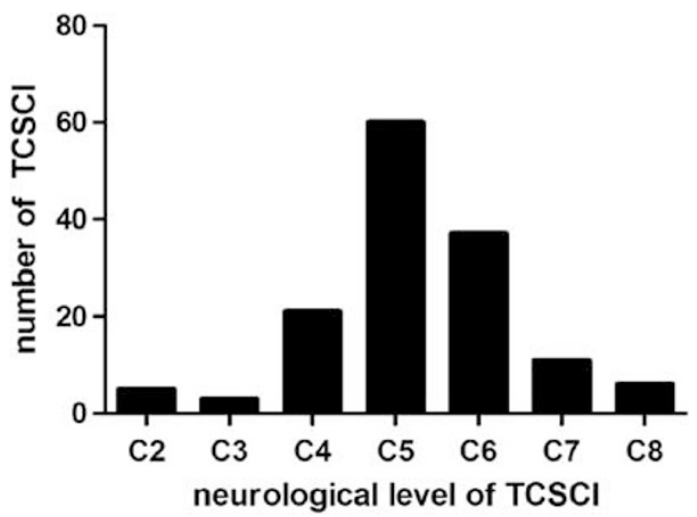

Figure 2 Percentage of persisting TCSCl by neurological level at admission.

Table 2 Number of TSCI according to the severity of injury, by the complication of $\mathrm{TCSCI}$

\begin{tabular}{llccr}
\hline Complication & ASIA A & \multicolumn{1}{c}{ ASIA B } & ASIA C & ASIA D \\
\hline Urinary infection & $1(12.5 \%)$ & $10(41.7 \%)$ & $8(29.6 \%)$ & $14(16.7 \%)$ \\
Respiratory infection & $1(12.5 \%)$ & $8(33.3 \%)$ & $8(29.6 \%)$ & $9(10.7 \%)$ \\
Hyponatremia & $5(62.5 \%)$ & $16(66.7 \%)$ & $10(37.0 \%)$ & $12(14.3 \%)$ \\
Bedsore & $1(12.5 \%)$ & $6(25.0 \%)$ & $3(15 \%)$ & $4(4.8 \%)$ \\
DVT & $0(0 \%)$ & $1(4.2 \%)$ & $1(3.7 \%)$ & $5(6.0 \%)$ \\
\hline
\end{tabular}

Abbreviations: ASIA, America Spinal Injury Association; DVT, deep venous thrombosis;

$\mathrm{TSCl}$, traumatic spinal cord injury.

trauma than any other area of the vertebral column. In the cervical vertebra, the most mobile motion segments are C4-C7, which were the most frequently injured.

As is well known, patients with TCSCI suffer from a higher number of complications, yet our data showed that the incidence of complications was lower than suggested in previous reports. For example, the incidence of respiratory complications was much lower than that in previous reports $(18.2 \%$ vs $63 \%),{ }^{19}$ and deep venous thrombosis was lower than that in Japan $(4.9 \%$ vs $21 \%) .{ }^{20}$ On the one hand, many complications were not recorded; moreover, preventive measures were taken in advance, such as the application of preventive anticoagulants before diagnosing a certain deep venous thrombosis. Additionally, as patients who died in the emergency apartment or in the process of transportation were not included, the mortality was much lower than that in other countries.
Nevertheless, this study has several limitations. (1) As a retrospective study, it was inevitable that some data might have been lost. To avoid this, we checked up all the related medical records to obtain data that are as complete as possible. (2) Patients aged 0-14 years were excluded. (3) Many complications were not diagnosed or recorded completely in medical records. (4) In addition, our mortality data were for inpatients only and patients who died before arriving at the hospital were not included. Despite these limitations, we still believe that this study contains valuable TCSCI epidemiological information, providing guidance for preventative measures.

\section{CONCLUSIONS}

This is a descriptive study of the characteristics of TCSCI patients admitted to Tianjin Medical University General Hospital from December 2008 to November 2011. The results revealed that TCSCI has its own characteristics. Falls were the leading causes, and TCSCI occurred most frequently in the middle-aged and elders. Along with the increasing proportion of older patients, the number of patients with TCSCI is growing. Therefore, establishing public policies aimed at preventing injuries should focus on falls and more attention should be paid to the aged owing to their vulnerability to low fall. In addition, complications should be prevented in TCSCI patients.

\section{DATA ARCHIVING}

There were no data to deposit.

\section{CONFLICT OF INTEREST}

The authors declare no conflict of interest.

\section{ACKNOWLEDGEMENTS}

We express our thanks to the staff of the Medical Record Room of Tianjin Medical University General Hospital for their help with collecting records data. This study was supported by grants from the Key Technology Foundation of Tianjin Health Bureau (07KG2), National Natural Science Foundation of China (30872603) and Research Foundation of Tianjin Health Bureau (09kz104).

1 Pickelsimer E, Shiroma EJ, Wilson DA. Statewide investigation of medically attended adverse health conditions of persons with spinal cord injury. J Spinal Cord Med 2010; 33: 221-231.

2 Baaj AA, Uribe JS, Nichols TA, Theodore N, Crawford NR, Sonntag VK et al. Health care burden of cervical spine fractures in the United States: analysis of a nationwide database over a 10-year period. J Neurosurg Spine 2010; 13: 61-66.

3 Wyndaele M, Wyndaele JJ. Incidence, prevalence and epidemiology of spinal cord injury: what learns a worldwide literature survey. Spinal Cord 2006; 44: 523-529.

4 Hagen EM, Eide GE, Rekand T, Gilhus NE, Gronning M. A 50-year follow-up of the incidence of traumatic spinal cord injuries in Western Norway. Spinal Cord 2010; 48: 313-318.

5 Couris CM, Guilcher SJ, Munce SE, Fung K, Craven BC, Verrier M et al. Characteristics of adults with incident traumatic spinal cord injury in Ontario, Canada. Spinal Cord 2010; 48: 39-44.

6 National Spinal Cord Injury Statistical Center. Available at: http://www.spinalcord. uab.edu. Accessed July 14, 2009

7 Ronen J, Itzkovich M, Bluvshtein V, Thaleisnik M, Goldin D, Gelernter I et al. Length of stay in hospital following spinal cord lesions in Israel. Spinal Cord 2004; 42: 353-358.

8 Tator $\mathrm{CH}$, Duncan EG, Edmonds VE, Lapczak LI, Andrews DF. Complications and costs of management of acute spinal cord injury. Paraplegia 1993; 31: 700-714.

9 Johnson RL, Brooks CA, Whiteneck GG. Cost of traumatic spinal cord injury in a population-based registry. Spinal Cord 1996; 34: 470-480.

10 Branco BC, Plurad D, Green DJ, Inaba K, Lam L, Cestero R et al. Incidence and clinical predictors for tracheostomy after cervical spinal cord injury: a National Trauma Databank review. J Trauma 2011; 70: 111-115.

11 Obalum DC, Giwa SO, Adekoya-Cole TO, Enweluzo GO. Profile of spinal injuries in Lagos, Nigeria. Spinal Cord 2009; 47: 134-137. 
12 Feng HY, Ning GZ, Feng SQ, Yu TQ, Zhou HX. Epidemiological profile of 239 traumatic spinal cord injury cases over a period of 12 years in Tianjin, China. J Spinal Cord Med 2011; 34: 388-394.

13 Ning GZ, Yu TQ, Feng SQ, Zhou XH, Ban DX, Liu Y et al. Epidemiology of traumatic spinal cord injury in Tianjin, China. Spinal Cord 2011; 49: 386-390.

14 Martin ND, Marks JA, Donohue J, Giordano C, Cohen MJ, Weinstein MS. The mortality inflection point for age and acute cervical spinal cord injury. J Trauma 2011; 71: 380-385; discussion 385-386.

15 Yoo DS, Lee SB, Huh PW, Kang SG, Cho KS. Spinal cord injury in cervical spinal stenosis by minor trauma. World Neurosurg 2010; 73: 50-52; discussion e4.

16 Chikuda H, Seichi A, Takeshita K, Matsunaga S, Watanabe M, Nakagawa Y et al. Acute cervical spinal cord injury complicated by preexisting ossification of the posterior longitudinal ligament: a multicenter study. Spine (Phila Pa 1976) 2011; 36 1453-1458.

17 Kurtaran A, Akbal A, Ersoz M, Selcuk B, Yalcin E, Akyuz M. Occupation in spinal cord injury patients in Turkey. Spinal Cord 2009; 47: 709-712.

18 Hoque MF, Hasan Z, Razzak ATMA, Helal SU. Cervical spinal cord injury due to fall while carrying heavy load on head: a problem in Bangladesh. Spinal Cord 2012; 50: 275-277.

19 Lemons VR, Wagner Jr FC. Respiratory complications after cervical spinal cord injury. Spine (Phila Pa 1976) 1994; 19: 2315-2320.

20 Sugimoto $Y$, Ito $Y$, Tomioka $M$, Tanaka M, Hasegawa $Y$, Nakago $K$ et al. Deep venous thrombosis in patients with acute cervical spinal cord injury in a Japanese population: assessment with Doppler ultrasonography. J Orthop Sci 2009; 14 374-376 